\title{
Cell Secretion: Current Structural and Biochemical Insights
}

\author{
Saurabh Trikha, Elizabeth C. Lee, and Aleksandar M. Jeremic* \\ Department of Biological Sciences, The George Washington University, \\ Washington, D.C. \\ E-mail: trikha@gmail.gwu.edu; eclee314@gwmail.gwu.edu; ierema@gwu.edu
}

Received April 8, 2010; Revised July 20, 2010, Accepted September 21, 2010; Published October 12, 2010

\begin{abstract}
Essential physiological functions in eukaryotic cells, such as release of hormones and digestive enzymes, neurotransmission, and intercellular signaling, are all achieved by cell secretion. In regulated (calcium-dependent) secretion, membrane-bound secretory vesicles dock and transiently fuse with specialized, permanent, plasma membrane structures, called porosomes or fusion pores. Porosomes are supramolecular, cupshaped lipoprotein structures at the cell plasma membrane that mediate and control the release of vesicle cargo to the outside of the cell. The sizes of porosomes range from 150 $\mathrm{nm}$ in diameter in acinar cells of the exocrine pancreas to $12 \mathrm{~nm}$ in neurons. In recent years, significant progress has been made in our understanding of the porosome and the cellular activities required for cell secretion, such as membrane fusion and swelling of secretory vesicles. The discovery of the porosome complex and the molecular mechanism of cell secretion are summarized in this article.
\end{abstract}

KEYWORDS: fusion pore-porosome, soluble N-ethylmaleimide-sensitive factor (NSF)attachment protein receptors (SNAREs), calcium $\left(\mathrm{Ca}^{2+}\right)$, potassium $\left(\mathrm{K}^{+}\right)$, chloride $\left(\mathrm{Cl}^{-}\right)$, membrane fusion, atomic force microscopy (AFM), transmission electron microscopy (TEM), electrophysiology, aquaporins, zymogen granules (ZG), synaptic vesicles (SVs), secretory vesicle swelling, cargo release, neurons, acinar cells

\section{INTRODUCTION}

Cell secretion is a fundamental cellular event implicated in the regulation of various physiological processes, such as neurotransmission, digestion of food, hormonal control of cell and reproductive cycles, and many other life processes. Cells produce and store products, including neurotransmitters, hormones, and digestive enzymes, in secretory vesicles and, upon demand, cells release vesicle cargo through a highly regulated process of cell secretion. Regulated vesicular release involves calcium ion $\left(\mathrm{Ca}^{2+}\right)-$ triggered membrane fusion of secretory vesicles with specialized structures at the cell plasma membrane called porosomes[1] and expulsion of vesicular content into the extracellular environment[2]. Besides $\mathrm{Ca}^{2+}$, an involvement of a specific set of cell secretory proteins, termed SNAREs (soluble Nethylmaleimide-sensitive factor [NSF]-attachment protein receptors), is also required for the fusion of secretory vesicles with porosomes[3,4]. SNAREs and $\mathrm{Ca}^{2+}$ have been proposed to serve as minimal membrane fusion machinery in cells[5,6]. Vesicle SNAREs (v-SNAREs) residing on vesicle membranes 
and target SNAREs (t-SNAREs) on the target plasma membranes (PM) interact to form a highly stable trans-SNARE complex to fuse opposing membranes and to release vesicle cargo. In many secretory cells, vesicles are recruited to the "active zones" of the target-releasing sites, but do not readily fuse in a wait for the $\mathrm{Ca}^{2+}$ signal. While SNAREs, $\mathrm{Ca}^{2+}$, and $\mathrm{Ca}^{2+}$-sensing proteins (or synaptotagmins) represent a central part of the regulated vesicular release process (with the express understanding that plant cells undergo membrane fusion, but lack synaptotagmins), we also discuss here the contributions of other players to the regulatory process in cell secretion.

Over the years, the term "fusion pore" has been referred to plasma membrane dimples that originate following a secretory stimulus, or to the continuity or channel established between opposing lipid membranes during membrane fusion. The "porosome", however, is a permanent, supramolecular, cupshaped lipoprotein structure at the cell plasma membrane, where secretory vesicles transiently dock and fuse to release intravesicular contents[1,8,9,10,11,12,13,14,15,16]. The SNARE-induced fusion of secretory vesicles at the porosome base involves the establishment of continuity between the opposing bilayers[9,10,14], which is conventionally referred to as "fusion pore". Hence, for clarity, the term "porosome" was assigned to this newly discovered structure at the cell plasma membrane $[9,10]$. In this review article, we summarize studies and discoveries that led to the elucidation of the porosome as universal cell secretory machinery and the key cellular components involved in regulated cell secretion.

\section{SIZE, STRUCTURE, AND COMPOSITION OF THE “POROSOME” CELL SECRETORY MACHINERY}

In the mid 1990s, atomic force microscopy (AFM) performed on isolated live pancreatic acinar cells in near physiological buffer solution provided, for the first time, the structural details and topology of the cell plasma membrane at nanometer resolution and in real time. AFM revealed circular structures termed "pits" that measure, on average, $400-500 \mathrm{~nm}$ in diameter and contain "depressions" that measure, on average, $100-180 \mathrm{~nm}$ in diameter and $25-45 \mathrm{~nm}$ in depth[1]. When pancreatic acinar cells were stimulated to secrete, the depressions enlarged by $25-30 \%$ in diameter and relative depth, and they returned to their resting size following completion of secretion. The enlargement of porosome diameter and the increase in its relative depth after exposure to secretagogue correlated with increased cargo (amylase) secretion. Conversely, exposure of pancreatic acinar cells to cytochalasin B, a fungal toxin that inhibits actin polymerization in cells, resulted in a 15-20\% decrease in porosome size and a consequent 50-60\% loss in secretion[1]. These results suggested the "depressions" to be the elusive fusion pores or porosomes in acinar cells of the exocrine pancreas[1]. Subsequent studies using growth hormonesecreting cells of the pituitary gland also demonstrated the presence of porosomes and the release of growth hormone through this elegant plasma membrane structure[7]. Sequel studies on other secretory chromaffin cells, mast cells, $\beta$-cells of the endocrine pancreas, and neural cells all demonstrated the presence of permanent porosome structures at their cell plasma membranes, and depicted the difference in their size (diameter): from $\sim 12-14 \mathrm{~nm}$ in neurons and astrocytes to $\sim 150-200 \mathrm{~nm}$ in endocrine and exocrine cells $[8,9,10,11,12,14,15]$. Porosomes in secretory cells exhibit characteristic cone/cup-shaped morphology, and the presence of a central plug in neurons and astrocytes[11,12,15]. AFM analysis of the synaptic membrane preparations revealed porosomes to be cup-shaped lipoprotein structures, consisting of eight vertical units or spokes symmetrically arranged around a central channel and the central plug (Fig. 1). Similarly, eightfold rotational symmetry and the eight spokes divided into two almost identical nucleoplasmic and cytoplasmic halves that span the nuclear membrane are the important structural attributes of the nuclear pore complex (NPC)[17,18]. While both transport systems share high symmetrical organization and display several structural elements that resemble each other, such as spokes and lateral membrane rings $[9,10,11,14,15,17,18]$, they are quite unique in their function. Whereas the nuclear pore acts as a sieve for the transport of molecules into and out of the nucleus[19], the porosome is exclusively for the regulated expulsion of intravesicular contents, resulting from the turgor pressure generated as a consequence of the rapid entry of water and ions into the secretory vesicle[20,21]. 

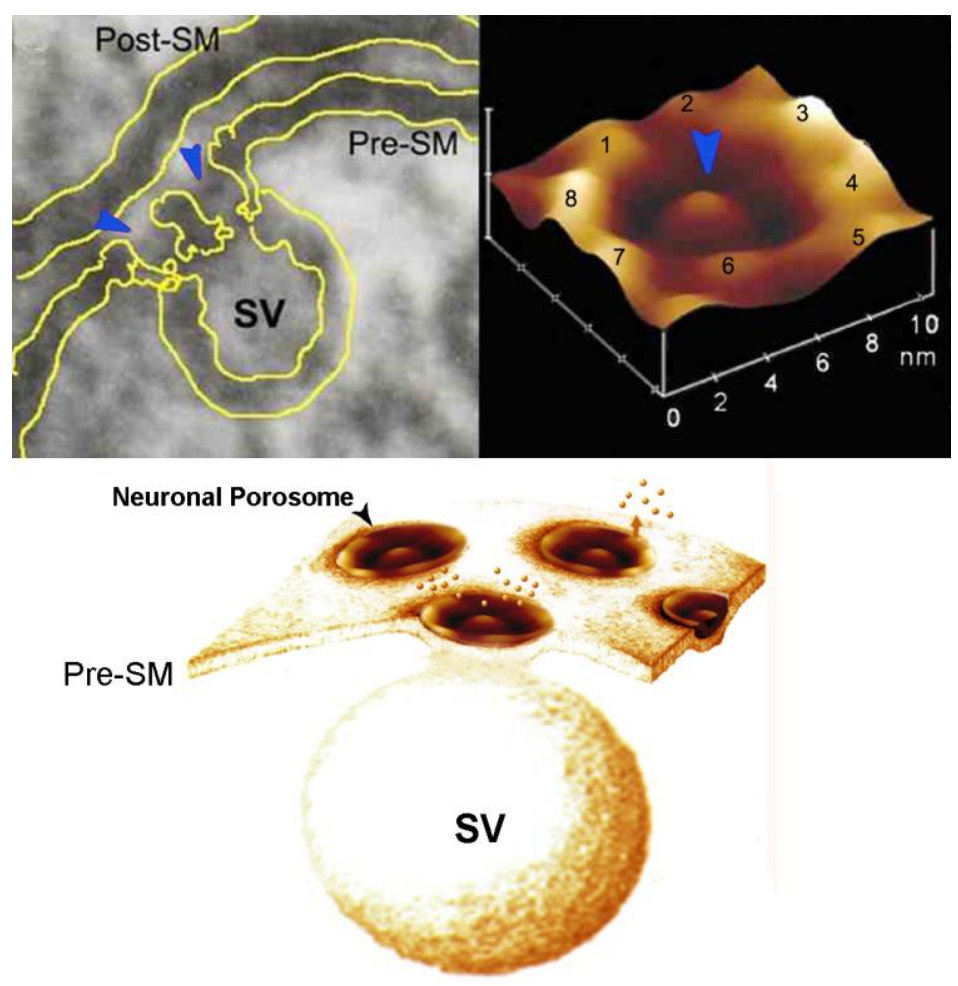

FIGURE 1. The neuronal porosome complex at the presynaptic membrane, where synaptic vesicles transiently dock and fuse to release neurotransmitters. The top left panel shows an electron micrograph with a $40-\mathrm{nm}$ diameter synaptic vesicle fused at the base of a 12-nm cup-shaped neuronal porosome with a central plug. The top right panel depicts an atomic force micrograph of a neuronal porosome with a central plug (indicated by arrowhead). The bottom panel is a schematic illustration of native neuronal porosome complexes at the presynaptic membrane and a transiently fused synaptic vesicle at its base during neurotransmitter release. (Courtesy of Prof. Bhanu P. Jena.)

These studies collectively suggest that secretory and nuclear transport machinery in eukaryotes have evolved to transfer molecules across membranes using similar architectural, yet unique, biophysical principles, but are further tuned to accommodate the size difference among various cargo molecules. Interestingly, in nature, even simple organisms like Toxoplasma gondii and paramecium have developed specialized and sophisticated secretory apparatuses, such as contractile vacuoles and secretory needles, to facilitate transport of molecules across their membranes[22,23,24]. Therefore, it is not surprising that mammalian cells have developed such highly sophisticated and specialized cup-shaped supramolecular lipoprotein structures, such as the porosome complexes and the porosome-like "canaliculi system" in human platelets[25,26], for the precise and regulated docking, fusion, and release of intravesicular contents from cells. In addition to the presence of the porosome as the universal secretory machinery at the cell plasma membrane, various forms of specialized structures, such as the T-bars at the Drosophila synapse[27] or the "beams," "ribs", and "pegs" at the frog neuromuscular junction[28], have evolved, each organized to facilitate a certain specialized secretory activity in different cell types.

Further insights into the structure and function of the fusion pore complex came from reconstituted studies in which the pancreatic porosome complex was immunoisolated and then structurally and functionally reconstituted into liposomes and bilayer membranes[9,10,11]. Both AFM and transmission electron microscopy (TEM) have demonstrated that pancreatic porosomes possess a basket-like morphology, with three lateral rings and several vertically arranged ridges or spokes[9]. TEM of the pancreatic porosome complex reconstituted into liposomes revealed a 150- to 200-nm, cup-shaped, 
basket-like structure similar to what is observed in its native state when coisolated with zymogen granules (ZGs)[10]. To test porosome functionality, Jena's group isolated porosomes from the exocrine pancreas or whole brain, reconstituted them into the lipid membrane of the electrophysiological bilayer setup, and then exposed them to isolated ZGs or synaptic vesicles. Upon addition of secretory vesicles to one of the compartments, both the capacitance and the current of the reconstituted membrane increased[10]. This increase in the electrical activity of the bilayer was followed by the release of ZG contents ( $\alpha$-amylase) to the adjacent compartment. Results from these experiments confirmed that the lipid membranereconstituted porosomes are indeed functional[9,10,11]. Several independent studies[13,16,29,30,31,32] confirmed the presence of porosome-like structures at secretory sites and their involvement in cell secretion in various secretory cells, including pituitary cells, neurons, and retinal pigment epithelium. EM study of neurons demonstrated docking of synaptic vesicles to $~ 12$ - to 15-nm electron-dense structures of presynaptic terminals[31]. Similarly, using EM, AFM, and high-molecular-weight dyes, other laboratories have also identified porosomes in acinar cells of the exocrine pancreas[29] and on gonadotrophs of the anterior pituitary gland[30]. In agreement with earlier AFM-TEM studies of the neuronal porosome[11,32], electron tomography analysis of presynaptic sites (Fig. 2) confirmed the presence of permanent, $\sim 15-\mathrm{nm}$, presynaptic densities to which synaptic vesicles (SVs) are attached[31]. These stable presynaptic structures could be neuronal fusion pores; however, the resolution power of electron tomography $(\sim 10 \mathrm{~nm})$ impeded their full structural analysis. Nevertheless, this 3D microscopy analysis of presynaptic sites revealed the morphological constraints exerted by the presynaptic molecular scaffold: SVs are tightly interconnected in the axonal bouton and this vesicle network is preferentially connected to the presynaptic densities in the active zones (AZ).

It is well established that SNARE proteins mediate membrane fusion in cells. If porosomes are the secretory sites for secretory vesicle docking and fusion, then plasma membrane-associated t-SNARES should localize at the bottom of this structure facing cytosol. An immuno-AFM study performed on inverted, inside-out, isolated pancreatic plasma membrane preparations has indeed demonstrated the selective localization of t-SNARE pancreatic isoform SNAP-23 to the porosome base, confirming that these permanent plasma membrane structures serve as secretory sites for vesicle docking and fusion in the pancreas[9]. Other studies have further demonstrated that neuronal t-SNARE syntaxin-1 regulates the release of neurotransmitters by lining the fusion pore in neurons[33]. Taken together, these studies demonstrate porosomes to be permanent supramolecular lipoprotein structures at the cell plasma membrane, where secretory vesicles transiently dock and fuse to release vesicle cargo[34,35].

The biochemical composition of the pancreatic and neuronal porosomes, and the distribution of various porosome proteins, have been recently determined using immunoprecipitation, immuno-AFM, and two yeast-hybrid studies[9,10,11,12,36]. Porosome composition has been implied from the mechanism of action of several inhibitors of vesicular release, such as clostridial toxins (SNAREs proteases), agatoxins $\left(\mathrm{Ca}^{2+}\right.$ channel antagonists), and cytochalasin D (actin depolarization agent). For instance, pretreatment of cells with the fungal toxin cytochalasin, a known inhibitor of actin polymerization, results in the collapse of the porosome and, consequently, inhibition of cell secretion[1]. This study clearly demonstrates actin to be a major component of the pancreatic porosome complex. Similarly, it has been demonstrated that plasma membrane-associated t-SNARE syntaxins-1/2 and SNAP-23/25, which are specifically degraded by Botulinum toxins $\mathrm{A}, \mathrm{C} 1$, and $\mathrm{E}$ [37], are integral parts of the pancreatic and neuronal porosome complexes[9,10,11]. In the pancreas, studies have shown that SNAP-23 localizes to the base (cytosolic side) of the porosome complex, where membrane-bound secretory vesicles dock and fuse with plasma membranes to release their cargo[10]. Furthermore, studies demonstrate the colocalization of voltagedependent $\mathrm{Ca}^{2+}$ channels (VGCCs) at release sites in a number of cells by using combined techniques of confocal imaging and electrophysiological recordings[38,39,40,41]. The association of syntaxin-1A, SNAP25 , and synaptotagmin with $\mathrm{N}-$, P/Q-, and L-type VGCCs is suggested from the results of coimmunoprecipitation experiments $[3,42,43,44,45,46]$. In vitro binding studies demonstrate that presynaptic $\mathrm{N}$ - and P/Q-type VGCCs interact directly with two presynaptic membrane proteins, syntaxin-1 and synaptotagmin, through a specific synprint (synaptic protein interaction) site at the II-III cytosolic domain both in a $\mathrm{Ca}^{2+}$-independent[42] and in a $\mathrm{Ca}^{2+}$-dependent manner[45,46]. The II-III domain of the 1c L-type 

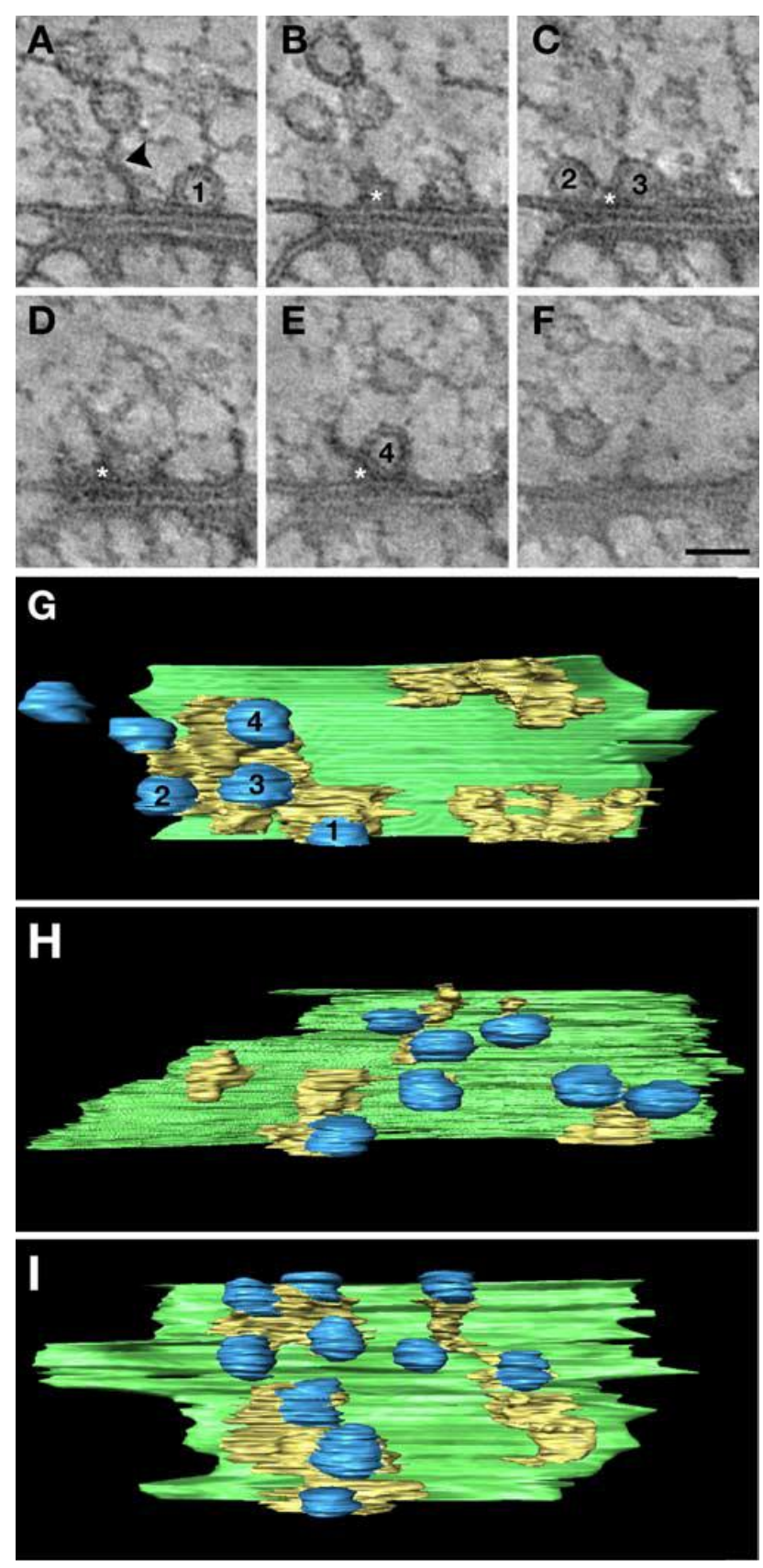

FIGURE 2. The three-dimensional (3D) architecture of the presynaptic cytomatrix. Association of docked SVs with presynaptic densities revealed by electron tomography. (A-F) Six virtual sections from a tomogram. The sections are separated by $\sim 19 \mathrm{~nm}$ in the $z$-axis. The docked SVs (numbered 1-4) are apposed to a presynaptic electron-dense material (asterisk). A filament (arrowhead) emerging from the electrondense material contacts an SV. (G-I) 3D reconstruction of the docked SVs (blue) and the presynaptic electron-dense material (yellow) in front of the postsynaptic density (green). $\mathrm{G}$ is the same synapse as in A-F. H and I are two other examples. Scale bars: A-F, $50 \mathrm{~nm}$. Reprinted with permission from Siksou et al.[31]. Copyright 2007 the Society for Neuroscience. 
$\mathrm{Ca}^{2+}$-channel subunit, which is predominantly expressed in endocrine and neuroendocrine cells, also binds syntaxin-1 and SNAP-25, but with lower affinity compared to the N and P/Q channels[44]. Furthermore, studies performed in Xenopus oocytes demonstrate a strong functional relationship between synaptic proteins and $\mathrm{Ca}^{2+}$ channels, since channels exhibit profoundly different kinetic properties in the presence and absence of SNAREs[44,47]. Along with functional studies, the proximity of $\mathrm{Ca}^{2+}$ channels to the releasing sites and the interaction of $\mathrm{Ca}^{2+}$ channels with synaptic proteins as revealed by in vitro binding assays further provide indirect, but strong, evidence of the physical interaction between these proteins. However, combined immunoprecipitation and two yeast-hybrid studies further revealed that the C-terminal domain of pancreatic SNAP-23 directly interacts with L-type $\mathrm{Ca}^{2+}$ channels in pancreatic membranes[36]. Consistent with this finding, studies demonstrated that the t-SNARE neuronal isoforms, syntaxin-1 and SNAP-25, physically interact with P/Q subtypes of $\mathrm{Ca}^{2+}$ channels in synaptic membranes[46]. These interactions are mediated by plasma membrane cholesterol[48]. Interestingly, in addition to mediating interactions of VGCCs with SNAREs[47,48,49,50,51], membrane cholesterol is also required for maintaining physical integrity and function of the porosome complex[12]. The finding that $\mathrm{Ca}^{2+}$ channels interact with SNAREs in a cholesterol-dependent manner in many secretory cells may explain, at least in part, the corresponding inhibitory effect of cholesterol-depleting agents and clostridial toxins on regulated $\left(\mathrm{Ca}^{2+}\right.$-dependent) vesicular release[52,53,54,55,56]. These seminal findings postulate that specific protein-sterol, protein-lipid, and protein-protein interactions regulate the assembly and function of the porosome on the plasma membranes. The importance of the proximity of the $\mathrm{Ca}^{2+}$ channel to the SNARE complex on cell plasma membranes and the role of $\mathrm{Ca}^{2+}$ and SNARE proteins in membrane fusion are discussed further in the text.

In addition to $\mathrm{Ca}^{2+}$ channels, SNAREs, and actin, other cytoskeletal proteins implicated in intracellular vesicle traffic have been found to associate with the porosome complex. For instance, $\alpha$ fodrin, which was previously implicated in exocytosis, has been shown to interact directly with tSNAREs[57]. Similarly, vimentin filaments interact with SNAP-23/25 to control the availability of free tSNAREs for assembly of the t-/v-SNARE complex[58]. Collectively, these findings suggest that the cytoskeleton proteins vimentin, $\alpha$-fodrin, and actin, along with SNAREs, are essential components of the porosome complex. Vesicle-associated proteins, such as v-SNAREs, synaptophysin, and myosin, may temporarily associate with the porosome when a secretory vesicle fuses with membranes. This association can occur through the globular tail domain of myosin V, which contains binding sites for VAMP and syntaxin[59,60]. Previously, the interaction of myosin V with syntaxin had been shown to require both $\mathrm{Ca}^{2+}$ and calmodulin[60]. It was also reported that VAMP acts as a myosin $\mathrm{V}$ receptor on secretory vesicles and may regulate formation of the SNARE complex[57]. Furthermore, it had been shown that synaptophysin interacts with the VAMP/myosin V complex[59]. In agreement with these earlier findings, current studies demonstrate that SNAP-23/25; syntaxin-1/2; the cytoskeletal proteins actin, $\alpha$-fodrin, and vimentin; and L- and $\mathrm{N}$-type $\mathrm{Ca}^{2+}$ channels, together with the SNARE regulatory protein NSF, associate with the pancreatic and/or neuronal porosome complexes[9,10,11,12]. Additionally, $\mathrm{Cl}^{-}$ion channels $\mathrm{ClC}_{2}$ and $\mathrm{ClC}_{3}$ have also been identified as part of both porosome complexes[10,11]. A number of other proteins and their isoforms identified as components of the porosome complex have also been reported using 2D-BAC gel electrophoresis[10]. Given the high specificity and complexity of the membrane fusion process, it is realistic to expect that the list of regulatory proteins and lipids associated with the porosome complex, including SNARE activators like synaptotagmins, Sec1, and Munc18, or inhibitors like complexins[61,62,63,64,65,66,67,68], will continue to grow.

\section{KINETIC, CONFORMATIONAL, AND ATOMISTIC INSIGHTS OF SNARE-MEDIATED $\mathrm{CA}^{2+}$-DRIVEN MEMBRANE FUSION PROCESS}

The first in vitro assay to study SNARE-mediated membrane fusion was developed by Rothman and coworkers[5]. This bulk liposome fusion assay demonstrated that SNAREs alone can fuse opposing membranes, albeit at a very slow rate $\left(\mathrm{t}_{1 / 2}=10-40 \mathrm{~min}\right)[5]$. However, the SNARE density in the 
reconstituted liposomes that investigators generally used in these early bulk liposome assays is currently considered too high (10 times higher than that in native membranes) to be physiologically relevant. The first direct demonstration of a key role for $\mathrm{Ca}^{2+}$ in SNARE-mediated membrane fusion was obtained in a study in which the authors used a similar reconstituted liposome model system, but used physiologically relevant t-/v-SNARE concentrations[6]. When neuronal t-SNARE and v-SNARE reconstituted liposomes interacted in the absence of $\mathrm{Ca}^{2+}$, fusion between opposing $\mathrm{t}-/ \mathrm{v}-\mathrm{SNARE}$ vesicles proceeded slowly, in the order of minutes $\left(\mathrm{t}_{1 / 2}=\sim 16 \mathrm{~min}\right)$, as previously reported[5]. In the presence of $\mathrm{Ca}^{2+}$, however, vesicles fused rapidly within seconds $\left(t_{1 / 2}=\sim 10 \mathrm{sec}\right)[6]$. The physiological relevance of these results can be inferred with a calculation by assuming the same rate $\left(\mathrm{k}=0.0911 \mathrm{sec}^{-1}\right)$ for fusion of liposomes in the presence of calcium[6] and for fusion of the native vesicles with the plasma membrane. With this assumption, the first $1 \%$ of vesicles from the cellular pool would fuse within $100 \mathrm{msec}$. In a neuroendocrine cell, using this same assumption, the time required for the fusion of the first vesicle with the plasma membrane, from a pool of 30,000 stored vesicles[69,70], would require less than $0.4 \mathrm{msec}$. This is consistent with the fact that, under physiological conditions, $\mathrm{Ca}^{2+}$ entry into the synapse triggers vesicle fusion and secretion from the readily releasable pool with a delay of only $0.1-0.5 \mathrm{msec}[71]$. Hence, this simple calculation shows that $\mathrm{Ca}^{2+}$-induced fusion of SNARE vesicles[6] is achieved in a physiologically relevant time scale. Subsequent studies confirmed the critical role of $\mathrm{Ca}^{2+}$ and the $\mathrm{Ca}^{2+}$ sensor protein synaptotagmin in the SNARE-mediated membrane fusion process[72,73]. Interestingly, the rate of $\mathrm{Ca}^{2+}$-induced membrane fusion of SNARE-reconstituted vesicles obtained in this study $\left(\mathrm{k}_{\text {fus }}=0.1^{\mathrm{s}-}\right.$ $\left.{ }^{1}[6]\right)$ is comparable to the rate of dissociation of SNARE-associated vesicles in the presence of NSF-ATP $\left(\mathrm{k}_{\mathrm{diss}}=1.1^{\mathrm{s}-1}[74]\right)$. In contrast, fusion of SNARE-reconstituted vesicles in the absence of $\mathrm{Ca}^{2+}$ proceeds at a much lower rate $\left(\mathrm{k}_{\text {fus }}=7 \times 10^{-4} \mathrm{~s}^{-1}[6]\right)$. Apparently, without $\mathrm{Ca}^{2+}$, the efficient regulation of an on/off cycle of SNARE assembly and disassembly at secretory sites would not be possible. This is particularly important during the release of neurotransmitters when synaptic vesicles transiently fuse with presynaptic membranes without a loss of identity, and/or when secretory vesicles undergo multiple rounds of release and refilling cycles at AZs, a process called "kiss and run"[75,76,77]. Hence, the presence of a potent fusogen $\left(\mathrm{Ca}^{2+}\right)$ and membrane fusion inhibitor (NSF-ATP) at secretory sites provides cells with the means to synchronize SNARE-mediated membrane fusion and release of vesicular content with vesicle cycling.

Do v-SNAREs and t-SNAREs interact in the same way in solution and on membranes? Do vSNAREs and t-SNAREs need to reside in opposing membranes in order to allow for membrane fusion? Recently, reconstituted studies have provided interesting answers to these questions[74,78,79,80,81,82]. Purified recombinant t-SNARE and v-SNARE proteins, when applied to the same lipid membranes or mica produced nonsymmetrical, globular-like cis-SNARE complexes that did not alter membrane electrical (conducting) properties[78]. In contrast, when t-SNARE vesicles were exposed to v-SNAREreconstituted bilayers (trans-SNARE conformation), symmetrical ring-like structures were demonstrated on the membranes[74,78]. Furthermore, an electrophysiological setup revealed the fusion of t-SNARE vesicles with v-SNARE-reconstituted bilayers, which was discernible by an increase in membrane capacitance and conductivity[78]. These data conclusively demonstrated that full-length t-SNAREs and vSNAREs need to reside and interact from opposing membranes in order to self-assemble into the physiologically relevant and fusion-competent t-/v-SNARE ring complexes. Although the crystal structure of the t-/v-SNARE complex is known[80], it should be kept in mind that atomic coordinates were determined for the postfusion cis-SNARE complex using recombinant t-SNARE and v-SNARE proteins that cannot produce functional, pore-forming complexes on membranes[74,78]. This necessitates the determination of the atomic structure of the membrane-associated trans-SNARE complex in an initial (prefusion) state. However, this remains a major challenge. Nevertheless, these structural studies provide valuable mechanistic insights into how assembly of SNARE complexes may mediate membrane fusion. Reconstituted studies further demonstrate that the disassembly of the SNARE complex, like its assembly, is a highly regulated process. The addition of the soluble NSF, an ATPase, and ATP, but not AMPPNP that is a nonhydrolyzable ATP analog, to preformed SNARE complex led to its rapid disassembly[74]. This study has shown that the t-/v-SNARE complex disassembly is an enzymatic and energy-driven 
process. Further analysis of NSF-ATP-induced disassembly of the SNARE complex by AFM has demonstrated NSF to function as a right-handed molecular motor[81].

The regulatory role of membranes and NSF-ATP in the assembly and disassembly of the t-/v-SNARE complex has also been recently investigated using spectroscopic approaches. Circular dichroism (CD) spectroscopy confirmed that secondary structures of membrane-associated SNAREs and SNARE complexes are different from those formed in the absence of membranes[82]. Specifically, CD spectroscopy revealed that V-SNAREs, when incorporated into liposomes, exhibit a reduced level of folding, characterized by a decrease in $\alpha$-helical content. Similar to v-SNAREs, the membrane-associated t-SNAREs exhibit less helical content than in suspension. Interestingly, there is no increase in the overall level of secondary structure upon complex formation. Rather, the CD spectra of the complexes are identical to a combination of individual spectra[82]. CD data support previous AFM results, which showed that lipid is required for the proper arrangement of the SNARE proteins in membrane fusion[74,79]. In the same study, the addition of NSF to the t-/v-SNARE complex results in an increase in the unordered fraction, which authors attributed to an overall disordered secondary structure of the NSF, and not necessarily to the unfolding of the t-/v-SNARE complex. In contrast, activation of NSF by the addition of ATP almost completely abolishes all R-helical content within SNARE complexes, indicating energy-driven disassembly of SNAREs[82]. These data are consistent with reports showing spontaneous assembly (coiling or zippering) of largely structured SNARE motifs into a helical t-/v-SNARE complex during membrane fusion[83,84]. In support of CD spectroscopy and electron paramagnetic resonance (EPR) data, a recent nuclear magnetic resonance (NMR) study of full-length v-SNARE synaptobrevin in micelles revealed mostly structured conformation of its SNARE motif[85]. SNARE motifs are conserved stretches of $\sim 70$ amino acids found in all SNAREs that spontaneously intertwine (coil) to form the core complex, which is thought to provide a force for the membrane fusion. The NMR study revealed that the structure of full-length synaptobrevin in micelles is segmented and dynamic, consisting of two transient helical segments flanked by disordered regions and a third more stable helix. Transient helixes 1 and 2 comprise the SNARE motif, whereas the more stable helix 3 is the transmembrane domain[85]. Based on these varied structural and motional properties along the synaptobrevin sequence, a nucleationpropagation mechanism for trans-SNARE complex formation has been proposed: helix-1 likely forms a nucleation site, the C-terminal disordered SNARE motif may arrest SNARE folding, whereas helix-2 likely couples SNARE complex folding and fusion[85]. In concordance with this proposed mechanism of the SNARE assembly, the progressive coiling of helices from their N-terminal ends toward the C-terminal transmembrane domains has been recently demonstrated[84]. The "zippering" of SNAREs may pull the two membranes into close apposition until they fuse. However, the energy released by SNARE complexes alone may not suffice to overcome hydration, electrostatic, and other repulsion forces. A recent study demonstrates that individual, membrane-bridging SNARE complexes provide much less pulling force and energy needed for membrane fusion than previously thought[86]. Thus, the molecular machinery that drives the $\mathrm{Ca}^{2+}$-dependent release of hormones and neurotransmitters may likely involve SNAREs, $\mathrm{Ca}^{2+}$, and a small soluble protein, complexin, described below. Besides regulating structure and conformation of the t-/v-SNARE complexes, membranes have also been found to control complex size, which is inversely proportional to the curvature of the vesicle. Larger vesicles have smaller curvatures and, consequently, they produce larger t-/v-SNARE complexes[79]. Thus, the circular arrangement of transSNARE complexes assembled on membranes limits surface area during fusion of opposing membranes, resulting in a restriction of channel size[78,79].

Does the distance at which t-SNAREs and v-SNAREs from opposing membranes interact have an effect on $\mathrm{Ca}^{2+}$-induced membrane fusion and, if yes, how? This question has been addressed by X-ray diffraction and molecular dynamics simulation studies using SNARE-reconstituted liposomes as a model system[6,87]. X-ray diffraction patterns of nonreconstituted vesicles revealed two broad peaks, the stronger one being at $3.1 \AA$ and the weaker centered at $1.9 \AA[6]$. The addition of $\mathrm{Ca}^{2+}$ and/or the incorporation of SNAREs at the vesicle membrane influenced both peaks within the 2.1- to 3.3- $\AA$ intensity range. The influence of $\mathrm{Ca}^{2+}$ and/or SNAREs was more visible on a peak positioned at $3.1 \AA$. The authors explained this finding in terms of an increased level of vesicle pairing and/or a decrease in 
the distance between apposed vesicles. Incorporation of t-SNARE and v-SNARE proteins at the vesicle membrane allowed for tight vesicle-vesicle interaction, which was demonstrated as a shift of reflection maximum from 3.1 to $2.9 \AA$. $\mathrm{Ca}^{2+}$ and SNAREs worked in a concerted manner to induce a much greater increase in peak intensity in the 2.9- to 3.1- $\AA$ range, with the appearance of shoulder at $2.8 \AA$. Taken together, these X-ray data suggest that trans-SNARE complex formation allows opposing bilayers to come within a distance of approximately $2.8 \AA[0]$. Using light scattering and X-ray diffraction experiments involving SNARE-reconstituted liposomes, it has become clear that fusion proceeds on physiologically relevant time scale only when $\mathrm{Ca}^{2+}$ ions are available between the t-SNARE- and vSNARE-apposed bilayers[6,74]. Because $\mathrm{Ca}^{2+}$ channels interact directly with t-SNAREs[47], and because t-SNAREs and v-SNAREs in opposing bilayers interact in a circular array to form conducting channels in the presence of $\mathrm{Ca}^{2+}[78,79]$, it would necessitate that $\mathrm{Ca}^{2+}$ ions are present between the SNARE-apposed bilayers to allow bridging of the opposing membranes. Once $\mathrm{Ca}^{2+}$ forms such a bridge, it can no longer hold its water shells, leading to bilayer dehydration, membrane destabilization, and fusion. In accordance with X-ray diffraction studies and the $\mathrm{Ca}^{2+}$-bridging hypothesis, molecular dynamic simulation studies have revealed that phospholipids and $\mathrm{Ca}^{2+}$ form DMP-Ca ${ }^{2+}$ complexes with the consequent removal of water[87]. As a result of DMP-Ca ${ }^{2+}$ interactions, the distance between the two DMP molecules is reduced to $2.92 \AA[87]$, which is in agreement with the 2.8 - $\mathrm{A}$ SNARE-induced apposition established between opposing lipid bilayers, reported from X-ray diffraction measurements[6]. Physicochemical studies performed in the 1980s by Papahadjopoulos and others also postulated the formation of such interbilayer $\mathrm{Ca}^{2+}$-phospholipids bridges[88,89,90].

In addition to its direct effect on phospholipid head groups, $\mathrm{Ca}^{2+}$ may also indirectly stimulate membrane fusion via activation of $\mathrm{Ca}^{2+}$ sensor proteins or synaptotagmins[71]. Synaptotagmins interact with SNARE complexes and phospholipids in a $\mathrm{Ca}^{2+}$-dependent manner, which in turns triggers synaptic fusion[61,65]. Although synaptotagmin is indispensible for regulated secretion (rapid and synchronous neurotransmitter release), it is actually not required for synaptic vesicle fusion[91]. Whether or not $\mathrm{Ca}^{2+}$ directly triggers membrane fusion, its presence is critical for regulated $\left(\mathrm{Ca}^{2+}\right.$-dependent $)$ secretory vesicle release. It is important to note here that, apparently, $\mathrm{Ca}^{2+}$ is not required for all membrane-fusion events in cells, such as constitutive (basal) vesicular release of hormones and neurotransmitters. Having described the catalyzing role of SNAREs and $\mathrm{Ca}^{2+}$ in membrane fusion, one may ask the following question: Is there a physiological blocker of SNARE-mediated, $\mathrm{Ca}^{2+}$-driven secretory vesicle fusion in cells? Recent studies demonstrate that indeed there is such a clamp or blocker termed "complexins"[64]. Complexins are $20-\mathrm{kDa}$ proteins that can associate with the SNARE complex, but not with individual SNAREs. At the cell plasma membrane, complexins compete with synaptotagmins for the binding sites on assembled SNARE complexes and when $\mathrm{Ca}^{2+}$ binds to the $\mathrm{Ca}^{2+}$ sensor synaptotagmin, the clamp is released, thereby allowing membrane fusion to proceed[66]. It has been demonstrated that the overexpression of complexin blocks membrane fusion in cells[66]. This led to the proposal that grappling proteins, synaptotagmin and claspin, act as a toggle switch of SNARE activity, allowing for the precise timing and regulation of the secretion of hormones and neurotransmitters[92]. These studies collectively provided a molecular understanding of the $\mathrm{Ca}^{2+}$-induced, SNARE-mediated, membrane-fusion process.

\section{MOLECULAR MECHANISMS OF SECRETORY VESICLE SWELLING AND VESICLE CONTENT EXPULSION}

Following membrane fusion, the continuity between the secretory vesicle and the extracellular solution is established, which allows the cell to release its vesicular content. In the case of synaptic fusion, this release is immediate $(<1 \mathrm{msec})$, which is needed to support the rapid process of neurotransmission[71]. The release of many hormones also takes place on a similar fast sec-time scale. The release of solutes is driven by the concentration gradient established between the lumen of the vesicle and the extracellular medium. However, the speed of neurotransmission and cell signaling obviously necessitates some form of facilitated or active transport to accelerate the release of neurotransmitters and hormones, rather than 
depending on an energetically favorable, but slow, passive diffusion process. Accumulating evidence suggests that vesicle swelling is the force that drives the expulsion of vesicular contents from cells[93,94,95,96,97,98,99,100,101]. In addition, it has been suggested from earlier electrophysiological measurements in mast cells[102,103,104,105] and from studies on bovine adrenal chromaffin cells[106] that secretory vesicle volume increases following stimulation of cell secretion. The dynamics of secretory vesicle swelling in live cells following a secretory stimulus was first demonstrated in acinar cells of the exocrine pancreas[107] and concomitantly in synaptic vesicles[2] using AFM. Time-lapse AFM imaging of live pancreatic acinar cells revealed the presence of docked ZGs, secretory vesicles in acinar cells, lying immediately below the surface of the apical plasma membrane[2]. Following the exposure to a secretory stimulus, the majority of ZGs within cells swelled, followed by a decrease in their size and a concomitant discharge of secretory products[2]. This study directly demonstrated two essential events: (1) intracellular swelling of secretory vesicles following stimulation of cell secretion in live cells and (2) the vesicle deflation following partial discharge of vesicular contents. Analogous to ZGs of the exocrine pancreas, the swelling of the SV was demonstrated during neurotransmitter release[2].

Hence, in light of the aforementioned, one key question remains: What is the molecular mechanism of secretory vesicle swelling? Recently, the molecular players involved in vesicle swelling in secretory cells have been identified. A direct observation of swelling of isolated ZGs in real time using AFM in combination with immunochemical analysis demonstrated the presence of chloride $\left(\mathrm{Cl}^{-}\right)$and ATPactivated potassium $\left(\mathrm{K}^{+}\right)$ion channels at the $\mathrm{ZG}$ membrane. The activities of these channels correlated with ZG swelling[108,109,110,111,112,113,114,115]. Release of ZG cargo ( $\alpha$-amylase) from pancreatic acinar cells required the presence of both $\mathrm{K}^{+}$and $\mathrm{Cl}^{-}$ions in the incubation medium[108,109]. The regulation of $\mathrm{K}^{+}$and $\mathrm{Cl}^{-}$ion channel activities by $\mathrm{G}_{\text {ai3 }}$ protein has been demonstrated in a number of tissues[116,117,118]. In a similar manner to the regulation of $\mathrm{K}^{+}$and $\mathrm{Cl}^{-}$ion channels at the cell plasma membrane, it was demonstrated that the heterotrimeric $\mathrm{G}_{\alpha \mathrm{i} 3}$ also regulates their channel-gating properties at the ZG membrane[119]. In this study, authors used the secretory stimulus mastoparan (Mas), an amphiphilic tetradecapeptide from wasp venom, to stimulate the GTP-ase activity of $\mathrm{G}_{\mathrm{i}} / \mathrm{G}_{\mathrm{o}}$ proteins[120,121,122]. Stimulation of $G$ proteins is believed to occur by insertion of the peptide into the phospholipid membrane and by adopting an $\alpha$-helical structure that resembles the intracellular loops of $\mathrm{G}$ protein-coupled receptors. An active mastoparan form,Mas-7, but not its inactive variant Mas-17, in the presence of $\left[{ }^{32} \mathrm{P}\right]$-labeled guanosine-5'-triphosphate (GTP) stimulated swelling and GTPase activity in ZGs, confirming the presence and activity of G proteins at the ZG membrane[119]. Similarly, Mas-7 has also been demonstrated to stimulate swelling of isolated brain synaptic vesicles[123]. Pancreatic ZGs swell rapidly in response to GTP and sodium fluoride (NaF)[119], which further postulated a G proteinmediated mechanism of secretory vesicle swelling. Following exposure of ZGs to these two G protein activators, a rapid water influx into ZGs and their concomitant swelling were observed[107,119]. As opposed to the slow diffusion by osmosis, membrane-associated water channels called aquaporins (AQP) are involved in rapid water gating in cells[124,125,126]. The presence of AQP1 at the ZG membrane[107], the presence of AQP6 and $\mathrm{G}_{\alpha o}$ protein at the synaptic vesicle membrane[123], and their involvement in GTP-mediated vesicle water gating and swelling have been demonstrated[107,123]. The involvements of additional contributors, phospholipase $\mathrm{A}_{2}$ in the swelling of ZGs and $\mathrm{vH}^{+}$-ATPase in the swelling of synaptic vesicles, have been also reported[21,127]. These studies demonstrate that mechanisms of water transport across the plasma and secretory vesicle membranes are quite similar. The sequence of events leading to swelling, however, remains to be determined.

To elucidate the role of swelling in vesicle plasma membrane fusion and in the expulsion of intravesicular contents, electrophysiological ZG-reconstituted lipid bilayer fusion assays have been performed. These studies demonstrate that, following stimulation of cell secretion, ZGs within pancreatic acinar cells swell, followed by a release of intravesicular contents through porosomes[2,10]. In contrast, isolated ZGs stay swollen following GTP exposure because there is no release of the intravesicular contents[2,107,119]. Within seconds following stimulation of secretion, empty and partially empty secretory vesicles accumulate within cells[128,129]. Reconstituted studies further revealed that different ZGs within cells or in isolation undergo different degrees of swelling when exposed to a certain 
concentration of secretory stimulus. More importantly, these studies demonstrated for the first time that there is a direct correlation between the extent of swelling and the amount of vesicle cargo released[2]. These observations may explain the graded release of hormones and neurotransmitters from cells when exposed to varying concentrations of secretory stimuli. The generation of empty secretory vesicles could result from multiple rounds of fusions-swelling-expulsion cycles during the secretory process. Another process termed "compound" secretion[130,131,132] may also contribute to partial release of intravesicular contents and the generation of partially empty vesicles. In compound secretion, secretory vesicles fuse with each other, allowing for larger content release through the single fusion pore. Because secretory sites (porosomes) at the cell plasma membrane are limited, to overcome this limitation during massive release, certain cells may reroute secretory vesicles to compound secretion. However, even via this mechanism of compound secretion, compound vesicles that fuse transiently with the plasma membrane[29,30,75,76,77,105,133,134,135,136,137,138,139] will eventually generate empty and partially empty vesicles following cell secretion. While the prevalence and relationship between two types of vesicular release remains to be determined, it has become clear that vesicle swelling is a necessary, priming step in the SNARE-mediated release of hormones, neurotransmitters, and other secretory products.

\section{CONCLUSION}

Studies summarized in this review highlight the importance and our current understanding of the cell secretory machinery, the porosome, how it operates at the cell plasma membranes, and the way it regulates the release of hormones and neurotransmitters from cells. Porosomes represent specialized plasma membrane structures, which are universally present in secretory cells, from exocrine and endocrine cells to neuroendocrine cells and neurons. Studies demonstrate that secretory vesicles transiently dock and fuse at the base of the porosome complex to release their cargo. Therefore, the secretory process in cells is a precisely coordinated, highly regulated, and well-orchestrated multistage event in which porosomes and secretory vesicle swelling play central roles.

\section{ACKNOWLEDGMENTS}

This work was supported by an Institutional Research Grant (IRG-08-091-01) from the American Cancer Society to The George Washington University Cancer Institute (to AJ).

\section{REFERENCES}

1. Schneider, S.W., Sritharan, K.C., Geibel, J.P., Oberleithner, H., and Jena, B.P. (1997) Surface dynamics in living acinar cells imaged by atomic force microscopy: identification of plasma membrane structures involved in exocytosis. Proc. Natl. Acad. Sci. U. S. A. 94, 316-321.

2. Kelly, M.L., Cho, W.J., Jeremic, A., Abu-Hamdah, R., and Jena, B.P. (2004) Vesicle swelling regulates content expulsion during secretion. Cell Biol. Int. 28, 709-716.

3. Bennett, M.K., Calakos, N., and Scheller, R.H. (1992) Syntaxin: a synaptic protein implicated in docking of synaptic vesicles at presynaptic active zones. Science 257, 255-259.

4. $\quad$ Sollner, T., Whiteheart, S.W., Brunner, M., Erdjument-Bromage, H., Geromanos, S., Tempst, P., and Rothman, J.E. (1993) SNAP receptors implicated in vesicle targeting and fusion. Nature 362, 318-324.

5. Weber, T., Zemelman, B.V., McNew, J.A., Westermann, B., Gmachl, M., Parlati, F., Sollner, T.H., and Rothman, J.E. (1998) SNAREpins: minimal machinery for membrane fusion. Cell 92, 759-772.

6. Jeremic, A., Kelly, M., Cho, J.A., Cho, S.J., Horber, J.K., and Jena, B.P. (2004) Calcium drives fusion of SNAREapposed bilayers. Cell Biol. Int. 28, 19-31.

7. Cho, S.J., Jeftinija, K., Glavaski, A., Jeftinija, S., Jena, B.P., and Anderson, L.L. (2002) Structure and dynamics of the fusion pores in live GH-secreting cells revealed using atomic force microscopy. Endocrinology 143, 1144-1148. 
8. Cho, S.J., Quinn, A.S., Stromer, M.H., Dash, S., Cho, J., Taatjes, D.J., and Jena, B.P. (2002) Structure and dynamics of the fusion pore in live cells. Cell Biol. Int. 26, 35-42.

9. Jena, B.P., Cho, S.J., Jeremic, A., Stromer, M.H., and Abu-Hamdah, R. (2003) Structure and composition of the fusion pore. Biophys. J. 84, 1337-1343.

10. Jeremic, A., Kelly, M., Cho, S.J., Stromer, M.H., and Jena, B.P. (2003) Reconstituted fusion pore. Biophys. J. 85, 2035-2043.

11. Cho, W.J., Jeremic, A., Rognlien, K.T., Zhvania, M.G., Lazrishvili, I., Tamar, B., and Jena, B.P. (2004) Structure, isolation, composition and reconstitution of the neuronal fusion pore. Cell Biol. Int. 28, 699-708.

12. Jeremic, A., Jin Cho, W., and Jena, B.P. (2006) Cholesterol is critical to the integrity of neuronal porosome/fusion pore. Ultramicroscopy 106, 674-677.

13. Matsuno, A., Itoh, J., Mizutani, A., Takekoshi, S., Osamura, R.Y., Okinaga, H., Ide, F., Miyawaki, S., Uno, T., Asano, S., Tanaka, J., Nakaguchi, H., Sasaki, M., and Murakami, M. (2008) Co-transfection of EYFP-GH and ECFPrab3B in an experimental pituitary GH3 cell: a role of rab3B in secretion of GH through porosome. Folia Histochem. Cytobiol. 46, 419-421.

14. Cho, W.J., Shin, L., Ren, G., and Jena, B.P. (2009) Structure of membrane-associated neuronal SNARE complex: implication in neurotransmitter release. J. Cell. Mol. Med. 13, 4161-4165.

15. Lee, J.S., Cho, W.J., Jeftinija, K., Jeftinija, S., and Jena, B.P. (2009) Porosome in astrocytes. J. Cell. Mol. Med. 13, $365-372$.

16. Tezel, T.H., Geng, L., Lato, E.B., Schaal, S., Liu, Y., Dean, D., Klein, J.B., and Kaplan, H.J. (2009) Synthesis and secretion of hemoglobin by retinal pigment epithelium. Invest. Ophthalmol. Vis. Sci. 50, 1911-1919.

17. Alber, F., Dokudovskaya, S., Veenhoff, L.M., Zhang, W., Kipper, J., Devos, D., Suprapto, A., Karni-Schmidt, O., Williams, R., Chait, B.T., Sali, A., and Rout, M.P. (2007) The molecular architecture of the nuclear pore complex. Nature 450, 695-701.

18. Brohawn, S.G., Leksa, N.C., Spear, E.D., Rajashankar, K.R., and Schwartz, T.U. (2008) Structural evidence for common ancestry of the nuclear pore complex and vesicle coats. Science 322, 1369-1373.

19. Fahrenkrog, B. and Aebi, U. (2003) The nuclear pore complex: nucleocytoplasmic transport and beyond. Nat. Rev. 4, 757-766.

20. Jena, B.P. (2009) Secretory vesicles transiently dock and fuse at the porosome to discharge contents during cell secretion. Cell Biol. Int. 34, 3-12.

21. Shin, L., Basi, N., Jeremic, A., Lee, J.S., Cho, W.J., Chen, Z., Abu-Hamdah, R., Oupicky, D., and Jena, B.P. (2010) Involvement of $\mathrm{vH}(+)$-ATPase in synaptic vesicle swelling. J. Neurosci. Res. 88, 95-101.

22. Hausmann, K. and Allen, R.D. (1976) Membrane behavior of exocytic vesicles. II. Fate of the trichocyst membranes in Paramecium after induced trichocyst discharge. J. Cell Biol. 69, 313-326.

23. Joiner, K.A. and Roos, D.S. (2002) Secretory traffic in the eukaryotic parasite Toxoplasma gondii: less is more. $J$. Cell Biol. 157, 557-563.

24. Kubori, T., Matsushima, Y., Nakamura, D., Uralil, J., Lara-Tejero, M., Sukhan, A., Galan, J.E., and Aizawa, S.I. (1998) Supramolecular structure of the Salmonella typhimurium type III protein secretion system. Science 280, 602605.

25. White, J.G. and Clawson, C.C. (1980) The surface-connected canalicular system of blood platelets--a fenestrated membrane system. Am. J. Pathol. 101, 353-364.

26. White, J.G. (1999) Platelet secretory process. Blood 93, 2422-2425.

27. Meinertzhagen, I.A., Govind, C.K., Stewart, B.A., Carter, J.M., and Atwood, H.L. (1998) Regulated spacing of synapses and presynaptic active zones at larval neuromuscular junctions in different genotypes of the flies Drosophila and Sarcophaga. J. Comp. Neurol. 393, 482-492.

28. Harlow, M.L., Ress, D., Stoschek, A., Marshall, R.M., and McMahan, U.J. (2001) The architecture of active zone material at the frog's neuromuscular junction. Nature 409, 479-484.

29. Larina, O., Bhat, P., Pickett, J.A., Launikonis, B.S., Shah, A., Kruger, W.A., Edwardson, J.M., and Thorn, P. (2007) Dynamic regulation of the large exocytotic fusion pore in pancreatic acinar cells. Mol. Biol. Cell 18, 3502-3511.

30. Savigny, P., Evans, J., and McGrath, K.M. (2007) Cell membrane structures during exocytosis. Endocrinology 148, 3863-3874.

31. Siksou, L., Rostaing, P., Lechaire, J.P., Boudier, T., Ohtsuka, T., Fejtova, A., Kao, H.T., Greengard, P., Gundelfinger, E.D., Triller, A., and Marty, S. (2007) Three-dimensional architecture of presynaptic terminal cytomatrix. J. Neurosci. 27, 6868-6877.

32. Cho, W.J., Ren, G., and Jena, B.P. (2008) EM 3D contour maps provide protein assembly at the nanoscale within the neuronal porosome complex. J. Microsc. 232, 106-111.

33. Han, X., Wang, C.T., Bai, J., Chapman, E.R., and Jackson, M.B. (2004) Transmembrane segments of syntaxin line the fusion pore of Ca2+-triggered exocytosis. Science 304, 289-292.

34. Cho, S.J., Wakade, A., Pappas, G.D., and Jena, B.P. (2002) New structure involved in transient membrane fusion and exocytosis. Ann. N. Y. Acad. Sci. 971, 254-256.

35. Jeremic, A. (2008) Cell secretion: an update. J. Cell. Mol. Med. 12, 1151-1154.

36. Cho, W.J., Jeremic, A., and Jena, B.P. (2005) Direct interaction between SNAP-23 and L-type Ca2+ channel. J. Cell. Mol. Med. 9, 380-386. 
37. Foran, P.G., Mohammed, N., Lisk, G.O., Nagwaney, S., Lawrence, G.W., Johnson, E., Smith, L., Aoki, K.R., and Dolly, J.O. (2003) Evaluation of the therapeutic usefulness of botulinum neurotoxin B, C1, E, and F compared with the long lasting type A. Basis for distinct durations of inhibition of exocytosis in central neurons. J. Biol. Chem. 278, 1363-1371.

38. Schroeder, T.J., Jankowski, J.A., Senyshyn, J., Holz, R.W., and Wightman, R.M. (1994) Zones of exocytotic release on bovine adrenal medullary cells in culture. J. Biol. Chem. 269, 17215-17220.

39. Bokvist, K., Eliasson, L., Ammala, C., Renstrom, E., and Rorsman, P. (1995) Co-localization of L-type Ca2+ channels and insulin-containing secretory granules and its significance for the initiation of exocytosis in mouse pancreatic beta-cells. EMBO J. 14, 50-57.

40. Robinson, I.M., Finnegan, J.M., Monck, J.R., Wightman, R.M., and Fernandez, J.M. (1995) Colocalization of calcium entry and exocytotic release sites in adrenal chromaffin cells. Proc. Natl. Acad. Sci. U. S. A. 92, 2474-2478.

41. Cuchillo-Ibanez, I., Michelena, P., Albillos, A., and Garcia, A.G. (1999) A preferential pole for exocytosis in cultured chromaffin cells revealed by confocal microscopy. FEBS Lett. 459, 22-26.

Charvin, N., L'Eveque, C., Walker, D., Berton, F., Raymond, C., Kataoka, M., Shoji-Kasai, Y., Takahashi, M., De Waard, M., and Seagar, M.J. (1997) Direct interaction of the calcium sensor protein synaptotagmin I with a cytoplasmic domain of the alpha1A subunit of the P/Q-type calcium channel. EMBO J. 16, 4591-4596.

43. Yang, S.N., Larsson, O., Branstrom, R., Bertorello, A.M., Leibiger, B., Leibiger, I.B., Moede, T., Kohler, M., Meister, B., and Berggren, P.O. (1999) Syntaxin 1 interacts with the L(D) subtype of voltage-gated Ca(2+) channels in pancreatic beta cells. Proc. Natl. Acad. Sci. U. S. A. 96, 10164-10169.

44. Wiser, O., Trus, M., Hernandez, A., Renstrom, E., Barg, S., Rorsman, P., and Atlas, D. (1999) The voltage sensitive Lc-type $\mathrm{Ca} 2+$ channel is functionally coupled to the exocytotic machinery. Proc. Natl. Acad. Sci. U. S. A. 96, 248253.

45. Sheng, Z.H., Rettig, J., Takahashi, M., and Catterall, W.A. (1994) Identification of a syntaxin-binding site on N-type calcium channels. Neuron 13, 1303-1313.

46. Sheng, Z.H., Rettig, J., Cook, T., and Catterall, W.A. (1996) Calcium-dependent interaction of N-type calcium channels with the synaptic core complex. Nature 379, 451-454.

47. Atlas, D. (2001) Functional and physical coupling of voltage-sensitive calcium channels with exocytotic proteins: ramifications for the secretion mechanism. J. Neurochem. 77, 972-985.

48. Taverna, E., Saba, E., Rowe, J., Francolini, M., Clementi, F., and Rosa, P. (2004) Role of lipid microdomains in P/Qtype calcium channel (Cav2.1) clustering and function in presynaptic membranes. J. Biol. Chem. 279, 5127-5134.

49. Xia, F., Gao, X., Kwan, E., Lam, P.P., Chan, L., Sy, K., Sheu, L., Wheeler, M.B., Gaisano, H.Y., and Tsushima, R.G. (2004) Disruption of pancreatic beta-cell lipid rafts modifies Kv2.1 channel gating and insulin exocytosis. J. Biol. Chem. 279, 24685-24691.

50. Xia, F., Leung, Y.M., Gaisano, G., Gao, X., Chen, Y., Fox, J.E., Bhattacharjee, A., Wheeler, M.B., Gaisano, H.Y., and Tsushima, R.G. (2007) Targeting of voltage-gated K+ and Ca2+ channels and soluble N-ethylmaleimide-sensitive factor attachment protein receptor proteins to cholesterol-rich lipid rafts in pancreatic alpha-cells: effects on glucagon stimulus-secretion coupling. Endocrinology 148, 2157-2167.

51. Xia, F., Xie, L., Mihic, A., Gao, X., Chen, Y., Gaisano, H.Y., and Tsushima, R.G. (2008) Inhibition of cholesterol biosynthesis impairs insulin secretion and voltage-gated calcium channel function in pancreatic beta-cells. Endocrinology 149, 5136-5145.

52. Pellegrini, L.L., O'Connor, V., Lottspeich, F., and Betz, H. (1995) Clostridial neurotoxins compromise the stability of a low energy SNARE complex mediating NSF activation of synaptic vesicle fusion. EMBO J. 14, 4705-4713.

53. Chang, J., Kim, S.A., Lu, X., Su, Z., Kim, S.K., and Shin, Y.K. (2009) Fusion step-specific influence of cholesterol on SNARE-mediated membrane fusion. Biophys. J. 96, 1839-1846.

54. Vikman, J., Jimenez-Feltstrom, J., Nyman, P., Thelin, J., and Eliasson, L. (2009) Insulin secretion is highly sensitive to desorption of plasma membrane cholesterol. FASEB J. 23, 58-67.

55. Shin, L., Cho, W.J., Cook, J.D., Stemmler, T.L., and Jena, B.P. (2010) Membrane lipids influence protein complex assembly-disassembly. J. Am. Chem. Soc. 132, 5596-5597.

56. Wang, N., Kwan, C., Gong, X., de Chaves, E.P., Tse, A., and Tse, F.W. (2010) Influence of cholesterol on catecholamine release from the fusion pore of large dense core chromaffin granules. J. Neurosci. 30, 3904-3911.

57. Nakano, M., Nogami, S., Sato, S., Terano, A., and Shirataki, H. (2001) Interaction of syntaxin with alpha-fodrin, a major component of the submembranous cytoskeleton. Biochem. Biophys. Res. Commun. 288, 468-475.

58. Goodson, H.V., Valetti, C., and Kreis, T.E. (1997) Motors and membrane traffic. Curr. Opin. Cell Biol. 9, 18-28.

59. Ohyama, A., Komiya, Y., and Igarashi, M. (2001) Globular tail of myosin-V is bound to vamp/synaptobrevin. Biochem. Biophys. Res. Commun. 280, 988-991.

60. Watanabe, M., Nomura, K., Ohyama, A., Ishikawa, R., Komiya, Y., Hosaka, K., Yamauchi, E., Taniguchi, H., Sasakawa, N., Kumakura, K., Ushiki, T., Sato, O., Ikebe, M., and Igarashi, M. (2005) Myosin-Va regulates exocytosis through the submicromolar Ca2+-dependent binding of syntaxin-1A. Mol. Biol. Cell 16, 4519-4530.

61. Fernandez-Chacon, R., Konigstorfer, A., Gerber, S.H., Garcia, J., Matos, M.F., Stevens, C.F., Brose, N., Rizo, J., Rosenmund, C., and Sudhof, T.C. (2001) Synaptotagmin I functions as a calcium regulator of release probability. Nature 410, 41-49. 
62. Dulubova, I., Yamaguchi, T., Gao, Y., Min, S.W., Huryeva, I., Sudhof, T.C., and Rizo, J. (2002) How Tlg2p/syntaxin 16 'snares' Vps45. EMBO J. 21, 3620-3631.

63. Yamaguchi, T., Dulubova, I., Min, S.W., Chen, X., Rizo, J., and Sudhof, T.C. (2002) Sly1 binds to Golgi and ER syntaxins via a conserved N-terminal peptide motif. Dev. Cell 2, 295-305.

64. Giraudo, C.G., Eng, W.S., Melia, T.J., and Rothman, J.E. (2006) A clamping mechanism involved in SNAREdependent exocytosis. Science 313, 676-680.

65. Pang, Z.P., Shin, O.H., Meyer, A.C., Rosenmund, C., and Sudhof, T.C. (2006) A gain-of-function mutation in synaptotagmin-1 reveals a critical role of $\mathrm{Ca} 2+$-dependent soluble N-ethylmaleimide-sensitive factor attachment protein receptor complex binding in synaptic exocytosis. J. Neurosci. 26, 12556-12565.

66. Tang, J., Maximov, A., Shin, O.H., Dai, H., Rizo, J., and Sudhof, T.C. (2006) A complexin/synaptotagmin 1 switch controls fast synaptic vesicle exocytosis. Cell 126, 1175-1187.

67. Dulubova, I., Khvotchev, M., Liu, S., Huryeva, I., Sudhof, T.C., and Rizo, J. (2007) Munc18-1 binds directly to the neuronal SNARE complex. Proc. Natl. Acad. Sci. U. S. A. 104, 2697-2702.

68. Shen, J., Tareste, D.C., Paumet, F., Rothman, J.E., and Melia, T.J. (2007) Selective activation of cognate SNAREpins by Sec1/Munc18 proteins. Cell 128, 183-195.

69. Parsons, T.D., Coorssen, J.R., Horstmann, H., and Almers, W. (1995) Docked granules, the exocytic burst, and the need for ATP hydrolysis in endocrine cells. Neuron 15, 1085-1096.

70. Plattner, H., Artalejo, A.R., and Neher, E. (1997) Ultrastructural organization of bovine chromaffin cell cortexanalysis by cryofixation and morphometry of aspects pertinent to exocytosis. J. Cell Biol. 139, 1709-1717.

71. Jahn, R. and Sudhof, T.C. (1999) Membrane fusion and exocytosis. Annu. Rev. Biochem. 68, 863-911.

72. Fix, M., Melia, T.J., Jaiswal, J.K., Rappoport, J.Z., You, D., Sollner, T.H., Rothman, J.E., and Simon, S.M. (2004) Imaging single membrane fusion events mediated by SNARE proteins. Proc. Natl. Acad. Sci. U. S. A. 101, 73117316.

73. Tucker, W.C., Weber, T., and Chapman, E.R. (2004) Reconstitution of Ca2+-regulated membrane fusion by synaptotagmin and SNAREs. Science 304, 435-438.

74. Jeremic, A., Quinn, A.S., Cho, W.J., Taatjes, D.J., and Jena, B.P. (2006) Energy-dependent disassembly of selfassembled SNARE complex: observation at nanometer resolution using atomic force microscopy. J. Am. Chem. Soc. 128, 26-27.

75. Aravanis, A.M., Pyle, J.L., Harata, N.C., and Tsien, R.W. (2003) Imaging single synaptic vesicles undergoing repeated fusion events: kissing, running, and kissing again. Neuropharmacology 45, 797-813.

76. Aravanis, A.M., Pyle, J.L., and Tsien, R.W. (2003) Single synaptic vesicles fusing transiently and successively without loss of identity. Nature 423, 643-647.

77. Harata, N.C., Choi, S., Pyle, J.L., Aravanis, A.M., and Tsien, R.W. (2006) Frequency-dependent kinetics and prevalence of kiss-and-run and reuse at hippocampal synapses studied with novel quenching methods. Neuron 49 , 243-256.

78. Cho, S.J., Kelly, M., Rognlien, K.T., Cho, J.A., Horber, J.K., and Jena, B.P. (2002) SNAREs in opposing bilayers interact in a circular array to form conducting pores. Biophys. J. 83, 2522-2527.

79. Cho, W.J., Jeremic, A., and Jena, B.P. (2005) Size of supramolecular SNARE complex: membrane-directed selfassembly. J. Am. Chem. Soc. 127, 10156-10157.

80. Sutton, R.B., Fasshauer, D., Jahn, R., and Brunger, A.T. (1998) Crystal structure of a SNARE complex involved in synaptic exocytosis at 2.4 A resolution. Nature 395, 347-353.

81. Cho, S.J. and Jena, B.P. (2007) N-ethymaleimide sensitive factor is a right-handed molecular motor. J. Biomed. Nanotechnol. 3, 209-221.

82. Cook, J.D., Cho, W.J., Stemmler, T.L., and Jena, B.P. (2008) Circular dichroism (CD) spectroscopy of the assembly and disassembly of SNAREs: the proteins involved in membrane fusion in cells. Chem. Phys. Lett. 462, 6-9.

83. Zhang, F., Chen, Y., Kweon, D.H., Kim, C.S., and Shin, Y.K. (2002) The four-helix bundle of the neuronal target membrane SNARE complex is neither disordered in the middle nor uncoiled at the C-terminal region. J. Biol. Chem. 277, 24294-24298.

84. Stein, A., Weber, G., Wahl, M.C., and Jahn, R. (2009) Helical extension of the neuronal SNARE complex into the membrane. Nature 460, 525-528.

85. Ellena, J.F., Liang, B., Wiktor, M., Stein, A., Cafiso, D.S., Jahn, R., and Tamm, L.K. (2009) Dynamic structure of lipid-bound synaptobrevin suggests a nucleation-propagation mechanism for trans-SNARE complex formation. Proc. Natl. Acad. Sci. U. S. A. 106, 20306-20311.

86. Wiederhold, K. and Fasshauer, D. (2009) Is assembly of the SNARE complex enough to fuel membrane fusion? $J$. Biol. Chem. 284, 13143-13152.

87. Potoff, J.J., Issa, Z., Manke, C.W., Jr., and Jena, B.P. (2008) Ca2+-dimethylphosphate complex formation: providing insight into Ca2+-mediated local dehydration and membrane fusion in cells. Cell Biol. Int. 32, 361-366.

88. Portis, A., Newton, C., Pangborn, W., and Papahadjopoulos, D. (1979) Studies on the mechanism of membrane fusion: evidence for an intermembrane $\mathrm{Ca} 2+-$ phospholipid complex, synergism with $\mathrm{Mg} 2+$, and inhibition by spectrin. Biochemistry 18, 780-790. 
89. Wilschut, J., Duzgunes, N., and Papahadjopoulos, D. (1981) Calcium/magnesium specificity in membrane fusion: kinetics of aggregation and fusion of phosphatidylserine vesicles and the role of bilayer curvature. Biochemistry $\mathbf{2 0}$, 3126-3133.

90. Laroche, G., Dufourc, E.J., Dufourcq, J., and Pezolet, M. (1991) Structure and dynamics of dimyristoylphosphatidic acid/calcium complexes by $2 \mathrm{H}$ NMR, infrared, spectroscopies and small-angle x-ray diffraction. Biochemistry 30, 3105-3114.

91. Geppert, M., Goda, Y., Hammer, R.E., Li, C., Rosahl, T.W., Stevens, C.F., and Sudhof, T.C. (1994) Synaptotagmin I: a major $\mathrm{Ca} 2+$ sensor for transmitter release at a central synapse. Cell 79, 717-727.

92. Sudhof, T.C. and Rothman, J.E. (2009) Membrane fusion: grappling with SNARE and SM proteins. Science 323, 474-477.

93. Tam, P.Y. and Verdugo, P. (1981) Control of mucus hydration as a Donnan equilibrium process. Nature 292, 340342.

94. Zimmerberg, J. and Whitaker, M. (1985) Irreversible swelling of secretory granules during exocytosis caused by calcium. Nature 315, 581-584.

95. Verdugo, P., Aitken, M., Langley, L., and Villalon, M.J. (1987) Molecular mechanism of product storage and release in mucin secretion. II. The role of extracellular Ca++. Biorheology 24, 625-633.

96. Verdugo, P., Deyrup-Olsen, I., Aitken, M., Villalon, M., and Johnson, D. (1987) Molecular mechanism of mucin secretion: I. The role of intragranular charge shielding. J. Dent. Res. 66, 506-508.

97. Verdugo, P. (1990) Goblet cells secretion and mucogenesis. Annu. Rev. Physiol. 52, 157-176.

98. Nanavati, C. and Fernandez, J.M. (1993) The secretory granule matrix: a fast-acting smart polymer. Science 259, 963-965.

99. Lim, S.K., Kwon, Y.H., Song, Y.D., Lee, H.C., Ryu, K.J., Huh, K.B., and Park, C.S. (1996) Swelling of the vesicle is prerequisite for PTH secretion. Yonsei Med. J. 37, 59-67.

100. Sugiya, H. and Matsuki, M. (2006) AQPs and control of vesicle volume in secretory cells. J. Membr. Biol. 210, 155159.

101. Herr, J.E., Winegard, T.M., O'Donnell, M.J., Yancey, P.H., and Fudge, D.S. (2010) Stabilization and swelling of hagfish slime mucin vesicles. J. Exp. Biol. 213, 1092-1099.

102. Curran, M.J. and Brodwick, M.S. (1991) Ionic control of the size of the vesicle matrix of beige mouse mast cells. $J$. Gen. Physiol. 98, 771-790.

103. Fernandez, J.M., Villalon, M., and Verdugo, P. (1991) Reversible condensation of mast cell secretory products in vitro. Biophys. J. 59, 1022-1027.

104. Monck, J.R., Oberhauser, A.F., Alvarez de Toledo, G., and Fernandez, J.M. (1991) Is swelling of the secretory granule matrix the force that dilates the exocytotic fusion pore? Biophys. J. 59, 39-47.

105. Alvarez de Toledo, G., Fernandez-Chacon, R., and Fernandez, J.M. (1993) Release of secretory products during transient vesicle fusion. Nature 363, 554-558.

106. Ornberg, R.L., Furuya, S., Goping, G., and Kuijpers, G.A. (1995) Granule swelling in stimulated bovine adrenal chromaffin cells: regulation by internal granule $\mathrm{pH}$. Cell Tissue Res. 279, 85-92.

107. Cho, S.J., Sattar, A.K., Jeong, E.H., Satchi, M., Cho, J.A., Dash, S., Mayes, M.S., Stromer, M.H., and Jena, B.P. (2002) Aquaporin 1 regulates GTP-induced rapid gating of water in secretory vesicles. Proc. Natl. Acad. Sci. U. S. A. 99, 4720-4724.

108. Fuller, C.M., Deetjen, H.H., Piiper, A., and Schulz, I. (1989) Secretagogue and second messenger-activated Clpermeabilities in isolated pancreatic zymogen granules. Pflugers Arch. 415, 29-36.

109. Fuller, C.M., Eckhardt, L., and Schulz, I. (1989) Ionic and osmotic dependence of secretion from permeabilised acini of the rat pancreas. Pflugers Arch. 413, 385-394.

110. Gasser, K.W., DiDomenico, J., and Hopfer, U. (1988) Secretagogues activate chloride transport pathways in pancreatic zymogen granules. Am. J. Physiol. 254, G93-99.

111. Gasser, K.W. and Hopfer, U. (1990) Chloride transport across the membrane of parotid secretory granules. Am. $J$. Physiol. 259, C413-420.

112. Piiper, A., Plusczyk, T., Eckhardt, L., and Schulz, I. (1991) Effects of cholecystokinin, cholecystokinin JMV-180 and GTP analogs on enzyme secretion from permeabilized acini and chloride conductance in isolated zymogen granules of the rat pancreas. Eur. J. Biochem. 197, 391-398.

113. Takuma, T., Ichida, T., Okumura, K., Sasaki, Y., and Kanazawa, M. (1993) Effects of valinomycin on osmotic lysis of zymogen granules and amylase exocytosis from parotid acini. Am. J. Physiol. 264, G895-901.

114. Thevenod, F., Gasser, K.W., and Hopfer, U. (1990) Dual modulation of chloride conductance by nucleotides in pancreatic and parotid zymogen granules. Biochem. J. 272, 119-126.

115. Thevenod, F., Chathadi, K.V., Jiang, B., and Hopfer, U. (1992) ATP-sensitive K+ conductance in pancreatic zymogen granules: block by glyburide and activation by diazoxide. J. Membr. Biol. 129, 253-266.

116. Kirsch, G.E., Codina, J., Birnbaumer, L., and Brown, A.M. (1990) Coupling of ATP-sensitive K+ channels to A1 receptors by $\mathrm{G}$ proteins in rat ventricular myocytes. Am. J. Physiol. 259, H820-826.

117. Ito, H., Tung, R.T., Sugimoto, T., Kobayashi, I., Takahashi, K., Katada, T., Ui, M., and Kurachi, Y. (1992) On the mechanism of $\mathrm{G}$ protein beta gamma subunit activation of the muscarinic $\mathrm{K}+$ channel in guinea pig atrial cell membrane. Comparison with the ATP-sensitive K+ channel. J. Gen. Physiol. 99, 961-983. 
118. Schwiebert, E.M., Kizer, N., Gruenert, D.C., and Stanton, B.A. (1992) GTP-binding proteins inhibit cAMP activation of chloride channels in cystic fibrosis airway epithelial cells. Proc. Natl. Acad. Sci. U. S. A. 89, 10623-10627.

119. Jena, B.P., Schneider, S.W., Geibel, J.P., Webster, P., Oberleithner, H., and Sritharan, K.C. (1997) Gi regulation of secretory vesicle swelling examined by atomic force microscopy. Proc. Natl. Acad. Sci. U. S. A. 94, 13317-13322.

120. Higashijima, T., Uzu, S., Nakajima, T., and Ross, E.M. (1988) Mastoparan, a peptide toxin from wasp venom, mimics receptors by activating GTP-binding regulatory proteins (G proteins). J. Biol. Chem. 263, 6491-6494.

121. Vitale, N., Mukai, H., Rouot, B., Thierse, D., Aunis, D., and Bader, M.F. (1993) Exocytosis in chromaffin cells. Possible involvement of the heterotrimeric GTP-binding protein G(o). J. Biol. Chem. 268, 14715-14723.

122. Konrad, R.J., Young, R.A., Record, R.D., Smith, R.M., Butkerait, P., Manning, D., Jarett, L., and Wolf, B.A. (1995) The heterotrimeric G-protein $\mathrm{Gi}$ is localized to the insulin secretory granules of beta-cells and is involved in insulin exocytosis. J. Biol. Chem. 270, 12869-12876.

123. Jeremic, A., Cho, W.J., and Jena, B.P. (2005) Involvement of water channels in synaptic vesicle swelling. Exp. Biol. Med. (Maywood) 230, 674-680.

124. Knepper, M.A. (1994) The aquaporin family of molecular water channels. Proc. Natl. Acad. Sci. U. S. A. 91, 62556258.

125. Marinelli, R.A., Pham, L., Agre, P., and LaRusso, N.F. (1997) Secretin promotes osmotic water transport in rat cholangiocytes by increasing aquaporin-1 water channels in plasma membrane. Evidence for a secretin-induced vesicular translocation of aquaporin-1. J. Biol. Chem. 272, 12984-12988.

126. Cho, M.R., Knowles, D.W., Smith, B.L., Moulds, J.J., Agre, P., Mohandas, N., and Golan, D.E. (1999) Membrane dynamics of the water transport protein aquaporin-1 in intact human red cells. Biophys. J. 76, 1136-1144.

127. Abu-Hamdah, R., Cho, W.J., Cho, S.J., Jeremic, A., Kelly, M., Ilie, A.E., and Jena, B.P. (2004) Regulation of the water channel aquaporin-1: isolation and reconstitution of the regulatory complex. Cell Biol. Int. 28, 7-17.

128. Lawson, D., Fewtrell, C., Gomperts, B., and Raff, M. (1975) Anti-immunoglobulin-induced histamine secretion by rat peritoneal mast cells studied by immunoferritin electron microscopy. J. Exp. Med. 142, 391-402.

129. Cho, S.J., Cho, J., and Jena, B.P. (2002) The number of secretory vesicles remains unchanged following exocytosis. Cell Biol. Int. 26, 29-33.

130. Matthews, G. and Sterling, P. (2008) Evidence that vesicles undergo compound fusion on the synaptic ribbon. $J$. Neurosci. 28, 5403-5411.

131. He, L., Xue, L., Xu, J., McNeil, B.D., Bai, L., Melicoff, E., Adachi, R., and Wu, L.G. (2009) Compound vesicle fusion increases quantal size and potentiates synaptic transmission. Nature 459, 93-97.

132. Vardjan, N., Jorgacevski, J., Stenovec, M., Kreft, M., and Zorec, R. (2009) Compound exocytosis in pituitary cells. Ann. N. Y. Acad. Sci. 1152, 63-75.

133. Taraska, J.W., Perrais, D., Ohara-Imaizumi, M., Nagamatsu, S., and Almers, W. (2003) Secretory granules are recaptured largely intact after stimulated exocytosis in cultured endocrine cells. Proc. Natl. Acad. Sci. U. S. A. 100, 2070-2075.

134. Tsuboi, T. and Rutter, G.A. (2003) Insulin secretion by 'kiss-and-run' exocytosis in clonal pancreatic islet beta-cells. Biochem. Soc. Trans. 31, 833-836.

135. Thorn, P., Fogarty, K.E., and Parker, I. (2004) Zymogen granule exocytosis is characterized by long fusion pore openings and preservation of vesicle lipid identity. Proc. Natl. Acad. Sci. U. S. A. 101, 6774-6779.

136. Chen, X., Wang, L., Zhou, Y., Zheng, L.H., and Zhou, Z. (2005) "Kiss-and-run" glutamate secretion in cultured and freshly isolated rat hippocampal astrocytes. J. Neurosci. 25, 9236-9243.

137. Obermüller, S., Lindqvist, A., Karanauskaite, J., Galvanovskis, J., Rorsman, P., and Barg, S. (2005) Selective nucleotide-release from dense-core granules in insulin-secreting cells. J. Cell Sci. 118, 4271-4282.

138. MacDonald, P.E., Braun, M., Galvanovskis, J., and Rorsman, P. (2006) Release of small transmitters through kissand-run fusion pores in rat pancreatic beta cells. Cell Metab. 4, 283-290.

139. Hanna, S.T., Pigeau, G.M., Galvanovskis, J., Clark, A., Rorsman, P., and MacDonald, P.E. (2009) Kiss-and-run exocytosis and fusion pores of secretory vesicles in human beta-cells. Pflugers Arch. 457, 1343-1350.

\section{This article should be cited as follows:}

Trikha, S., Lee, E.C., and Jeremic, A.M. (2010) Cell secretion: current structural and biochemical insights. TheScientificWorldJOURNAL 10, 2054-2069. DOI 10.1100/tsw.2010.193. 

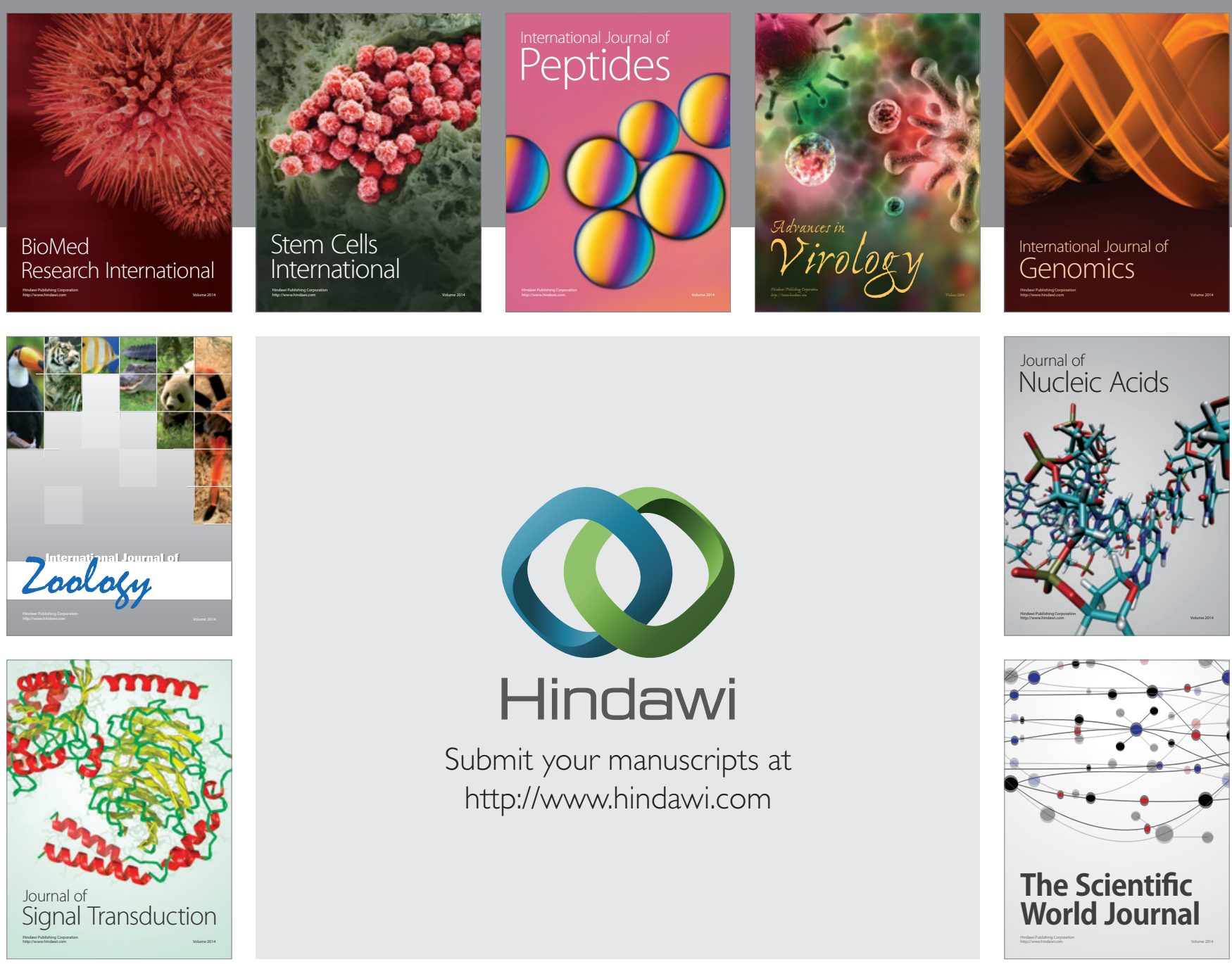

Submit your manuscripts at

http://www.hindawi.com
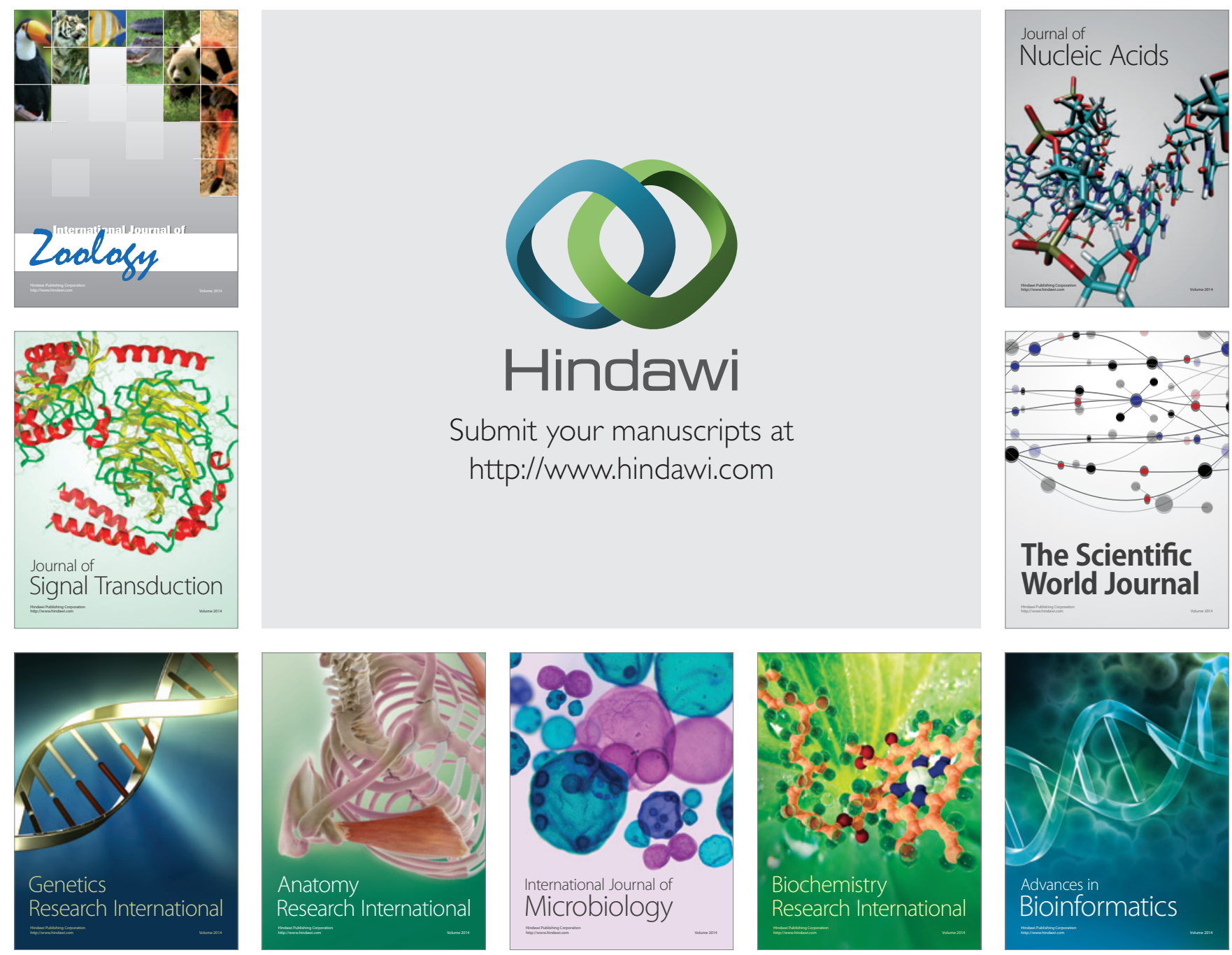

The Scientific World Journal
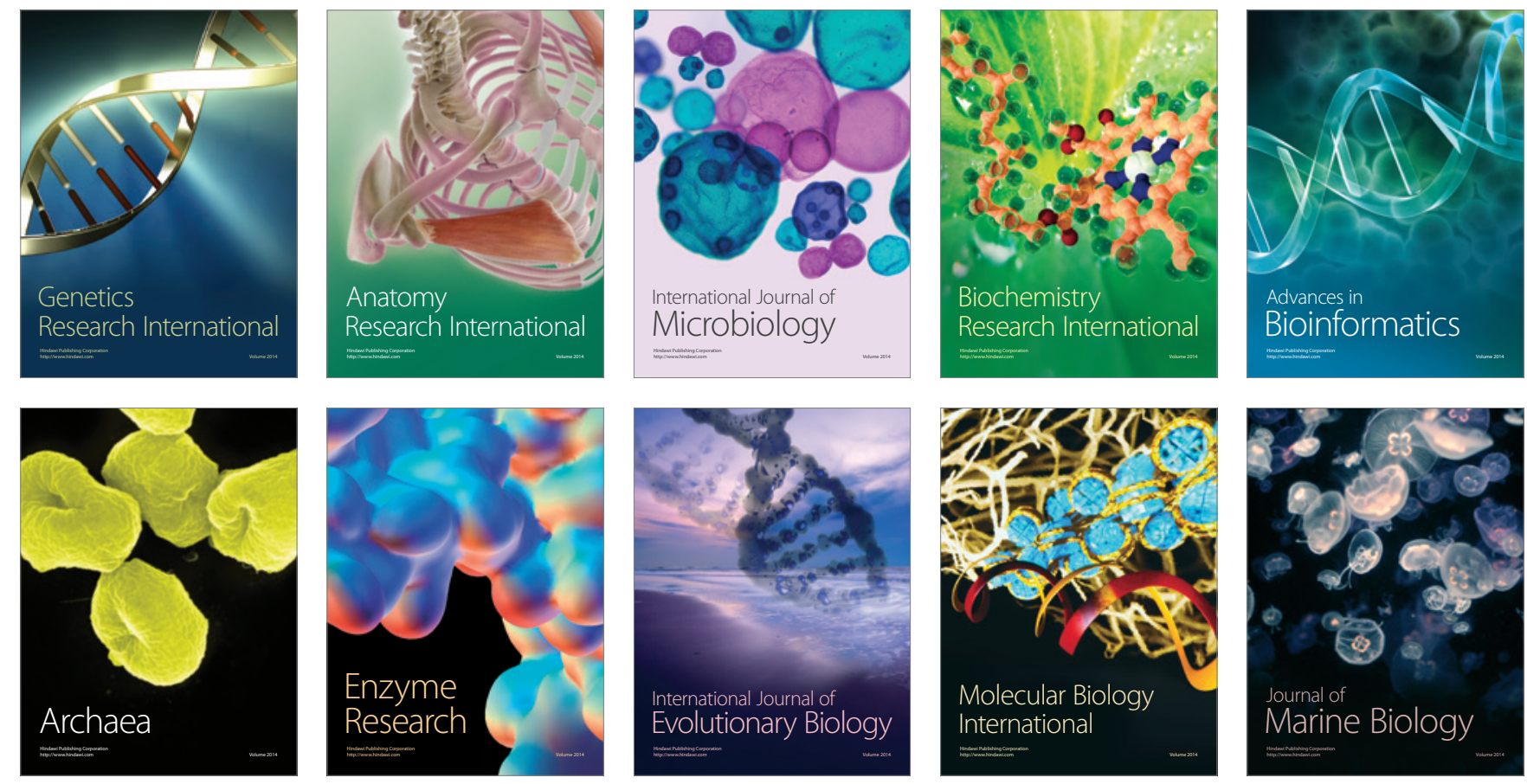